\title{
THE IMPACT OF BEDTIME COMPULSIVE SOCIAL MEDIA USE ON STUDENTS' QUALITY OF SLEEP IN THE COPPERBELT COLLEGES OF EDUCATION, ZAMBIA
}

\author{
Akakandelwa Akakandelwa \\ Senior lecturer, \\ Department of Library and Information Science, \\ University of Zambia
}

\author{
Harry Jordan Silomba \\ Lecturer, \\ Department of Education; \\ Educational Psychology. \\ Mufulira College of Education
}

Article DOI: $\underline{\text { https://doi.org/10.36713/epra6502 }}$

\begin{abstract}
This study investigated the relationship between bedtime Compulsive Social Media Use (CSMU) on students' sleep quality in the Copperbelt Colleges of Education, Zambia. Mixed method was utilised to solicit data from a sample of five hundred and seventy-nine (579) college students who were drawn from three (3) public and three (3) private colleges. Bergen Social Media Addiction Scale (BSMAS) and Pittsburgh Sleep Quality Index (PSQI) scale were utilised for data collection. Quantitative data were analysed using Statistical Package for the Social Science, whereas qualitative data was analysed using thematic analysis. Findings showed provision of pleasure as motive that compiled students to use social media during bedtime. Besides, it was established that students were spending less than 8 hours of sleep. However, the negative correlation between CSMU and sleep quality was evident. Therefore, the study recommends that college managements should conduct awareness programs to educate students on the negative effects of excessive usage of social media, particularly during bedtime.
\end{abstract}

KEY WORDS: Bedtime; Social Media; College Students; Quality of Sleep; Copperbelt Zambia.

\section{INTRODUCTION}

Social media is a prevalent communication channel that is extremely fast, broad and compelling (Dearborn, 2014). Until now, it has spread across the globe with remarkable speed, and several studies have reported a rapid increase in social media accessibility and usage (Smith \& Anderson, 2018; Statista, 2019; Kemp, 2021). Besides, social media users have continued to surge, with nearly half a billion new users within a short period taking the global total to almost 4.2 billion by the start of 2021 (Kemp, 2021). A regulatory body called Zambia Information and Communications Technology Authority (ZICTA, 2018) reveals a steady growth in the adoption and utilisation of social media among Zambians. For example,
Zambia's amount of social media consumers extended by 360 thousand $(+19 \%)$ between April 2019 and January 2020 (Kemp, 2021). Social media progression in Zambia remained at 13\% in January 2020, and it has been accounted for to be on the increase among Zambians youthful population (Akakandelwa \&Walubita, 2017; Kemp, 2021; Silomba et al., 2021). The growing affordability of more advanced mobile technologies such as handheld devices (smartphones and tablets), computers and mobile data has increased social media access. Subsequently, the geometric increase in social media connectivity and networking improvement from $2 \mathrm{G}, 3 \mathrm{G}, 4 \mathrm{G}$, and the projected $5 \mathrm{G}$ mobile broadband has also increased the students' demand for social media accessibility. 
One of the most striking consequences arising from the unprecedented upsurge in social media use seems to be a fundamental change in how students deal with social media during bedtime in today's pervasive technology. Instead of using it to get in touch with others or for provision of entertainment only at certain points in time and for a specific amount of time, many students have now engaged in the habit of being almost permanently online, even during bedtime (Lund et al., 2010; Vorderer et al., 2016; Scott et al., 2019), a trend purported to induce poor quality of sleep (Bhat, 2017; Oche et al., 2019).

As literature holds, poor quality of sleep is caused by a host of reasons which has numerous negative consequences (Lund et al., 2010; Vorderer et al., 2016; Garett et al., 2018; Scott et al., 2019), and it is often termed either acute sleep deprivation or chronic partial sleep deprivation (Lund et al., 2010). Sleep plays a huge role in the healthy lifestyle of an individual, but with todays' surge in social media usage, several upcoming factors may deter this vital function, causing poor quality of sleep. Many college students access social media daily. In that case, social media has become a significant part of their lives. At present, as all information is instantly available on social media platforms, it becomes challenging to disregard it even during bedtime. As Vorderer et al. (2016) advanced, social media users desire to stay engaged online and habitually prefer to keep their smartphones in closeness, even during bedtime, to ensure quick responses to their friends online. As such, social networking has become a daily practice in almost every student, which in turn adversely affects their sleep patterns (Scott et al., 2019).

Studies have reported that the number of social media friend student be-friend may also account for why students sleep late (Bhat, 2017). This occurs for multiple reasons; however, it is essential to note that quantity and quality of sleep are often situationdependent, with many aspects of the students' activities exacerbating it. For example, some studies indicate that students stay awake because of their gratification of chatting online, attending to oncoming messages immediately, checking on updates, or reaching the next game levels (Sharma \& Shukla, 2016; Cramer \& Inkster, 2017). Another related study done by Buran \& Doğan (2018) discovered that students had more than 250 friends. In contrast, Petersen \& Johnston (2015) asserted that student had between 301 to 400 Facebook friends. Furthermore, Johnston et al. (2013) indicated that students at a university in South Africa had between 100-150 Facebook friends. Although the numbers of followers varied, we can argue that just having more than 100 followers makes a student be too overwhelmed during bedtime social networking.

Reliable information that has been documented in other countries revealed significantly sleep problems due to inadequate sleep among the students (Adams et al., 2016; Abdalqader et al., 2018; Oche et al., 2019). A study conducted by Nasirudeen et al. (2017) reported that an overwhelming number (97.6\%) of students used to sleep less than 7 hours. Subsequently, an earlier study was done by Lund et al. (2010) in Virginia, USA, reported that the majority of the college students were sleeping less than 8 hours. This showed that students used to prolong their stay on social media, especially in bed, and the trend had to yield adverse effects on students' daytime sleepiness. However, the empirical evidence seems to be problematic. For example, the American Academy of Sleep Medicine and Sleep recommend between 8 to 9 hours per night regularly for young adults (Hirshkowitz et al., 2015; Watson et al., 2015). Sleep length suggestions given by such specialists are fundamental guidelines and help inform the populace regarding mediations, approaches, and healthy sleep practices (Hirshkowitz et al., 2015).

As earlier indicated, students' CSMU could result in negative consequences, which in turn affects the quality of sleep (Garett et al., 2018; Lin et al., 2019). Some adverse effects may arise from behavioural, whereas others may be generated by physiologic (Hershner \& Chervin, 2014; Garett et al., 2018; Scott et al., 2019). For example, studies indicate that CSMU around bedtime is associated with reasons students develop difficulties falling asleep, repeated awakenings, or waking up too early (Hershner \& Chervin, 2014). Most young adults prefer to leave their phone on during sleep, with only a few turning it to silent or vibrate modes (Hershner \& Chervin 2014). Equally, a study that was done by Levenson et al. (2017) in the USA reported that CSMU during the day might displace time that was intended to be given to finishing various tasks (Levenson et al., 2017). The situation has been consistently voiced by other scholars who showed that time spent using social media might dislodge other daytime exercises as such school work that is then postponed and upset bedtime schedules (Vorderer et al., 2016; Scott et al., 2019).

Besides, other studies have also advanced physiological aspects as reasons that make students experienced more challenging to fall asleep. For example, Oche et al. (2019) surveyed the prevalence and effect of social media on sleep among Nigeria students. They indicated that more than half of the students complained of poor sleep quality, fatigue, and sleepiness during the day and difficulty coping with academic activities. Consequently, it is conceivable that 
students are bound to stay watchful for incoming online media alarms or react to these during bedtime, thus exacerbating excitement and eye pains due to prolonged exposure to phone light that adds to difficulties falling asleep once more (Garett et al., 2018).

Regarding the direction on the relationship between social media use and quality of sleep, Lin et al. (2019) carried a cross-sectional study to investigate its relationship, using a total sample of 503 students in Taiwan. The study's findings demonstrated a significant negative association between the degree of Internet addiction and sleep quality. In another related study, Yang et al. (2019) revealed that up to 95\% of respondents were in the routine of using their smartphones before their sleep. The study showed a negative correlation between smartphone dependence and sleep duration. Given the evidence from other parts of the globe, it may be assumed that the situation may also be apparent in Zambian. However, until now, there has been a shortage of studies investigating the aspect of CSMU and quality of sleep in the context of students on the Copperbelt Province of Zambia. In an attempt to fill up the observed gap, three questions were raised as guides. These include:

1. What are the reasons behind students' use of social media at night?

2. How much time do students spend at night sleeping after using social media?

3. What relationship exists between students CSMU at night and sleep quality?

\section{SIGNIFICANT OF THE STUDY}

Social media use has become one of the leading daily activities of college students. However, there is a dearth of literature on various aspects of social media, particularly on the quality of sleep, which is now a vital part of many college students' lives in Zambia. As such, the findings may help generate public awareness of the adverse effects of CSMU on sleep quality. It may also better support realistic discussions on best practices that consider the context of current students' social media norms. Lastly, the study may also stimulate more investigation in a similar field.

\section{METHODOLOGY}

The research employed the interpretive and positivist paradigm, a mixed-methods approach to carry out the research. The two approaches provide insight into the research problem than the single-handed system (Baskarada \& Koronios, 2018). From this understanding, it's undoubtedly that the truth from the two standpoints closes up gaps in one approach by the other (Creswell \& Creswell, 2018). Data was solicited from a sampled of five hundred and seventy-nine (579) college students who were drawn from three (3) public and three (3) private colleges of education on the Copperbelt. Two sampling techniques were utilised to draw the sample, that is, stratified random and simple random sampling. Modified Bergen Social Media Addiction Scale (BSMAS), a self-reporting survey, was used to assess students' CSMU (Silomba et al., 2021). Similarly, the Pittsburgh Sleep Quality Index (PSQI) was used for poor sleep data collection quality. PSQI scale developed by Buysse et al. (1989) is a commonly used instrument to evaluate sleep quality and is believed to be valid and reliable (Xu et al., 2016; Zhang et al., 2016). The scale has 19 questions and seven clinical themes. It includes subjective sleep quality, sleep latency, sleep duration, habitual sleep efficiency, sleep disturbance, sleeping medication and daytime sleepiness (Cole et al., 1989). The benchmark for measurement is that the higher the score, the poorer the quality of sleep. In the current study, six-items were adapted and utilised. Cronbach alpha for overall sleep quality was .846 in the present study. Data obtained was analysed using the Statistical Package for the Social Science, Version 23 and thematic analysis. The strength of the correlation between CSMU and poor sleep quality was measured based on Akoglu (2018) guidelines. The researchers obtained ethical clearance from the University of Zambia (UNZA) ethical clearance committee, and the Ministry of General Education authorised permission to conduct the study in the sampled colleges.

\section{RESULTS \\ Respondent's Demographic Characteristics (Quantitative)}

Six hundred questionnaires were circulated; out of which 579 were returned, yielding a response rate of $96.5 \%$. Table 1 presents the respondents' demographic characteristics broken down as follows: 434 (74.9\%) of the respondents were from public colleges, and 145 $(25.1 \%)$ were from private colleges. Two hundred and ninety-two (50.4\%) were females, and 287 (49.6\%) were males. Furthermore, 92 (15.9\%) were aged 19-20 years, $327(56.5 \%)$ were aged 21-25, and $160(27.6 \%)$ were over 26 years old. Besides, most of the respondents $(73.7 \%)$ were single, while only $26.3 \%$ were married. 
Table 1: Demographic Characteristics

\begin{tabular}{|c|c|c|c|}
\hline Variables & Values & Frequency $(\mathrm{n}=579)$ & Percentage \\
\hline \multirow{2}{*}{ College status } & Public & 434 & $74.9 \%$ \\
\cline { 2 - 4 } & Private & 145 & $25.1 \%$ \\
\hline \multirow{2}{*}{ Gender } & Male & 287 & $49.6 \%$ \\
\cline { 2 - 4 } & Female & 292 & $50.4 \%$ \\
\hline \multirow{3}{*}{ Gge in years } & $19-20$ & 92 & $15.9 \%$ \\
\cline { 2 - 4 } & $21-25$ & 327 & $56.5 \%$ \\
\cline { 2 - 4 } & Above 26 & 160 & $27.6 \%$ \\
\hline \multirow{2}{*}{ Marital Status } & Married & 152 & $26.3 \%$ \\
\cline { 2 - 4 } & Single & 427 & $73.7 \%$ \\
\hline
\end{tabular}

Discussant' Demographic Characteristics (Qualitative)

Forty-two discussants (18 females and 24 males) participated in the FGDs, which comprised six groups. To ensure confidentiality, the discussants are represented by the symbol: FGD 1, 2, 3, 4, 5, and 6 . The numbers 1 to 6 are symbols for a college where the discussants were drawn.
Social media use and Student's quantity of sleep

Student's degree of social media usage

Respondents were asked to rate themselves regarding the magnitude of their usage of social media at night in the past one year, most of the respondents $(55.3 \%)$ rated themselves very heavy users of social media, whereas $25.9 \%$ of the respondents rated themselves heavy users. Equally, $14.7 \%$ of the respondents rated themselves, moderate users of social media, while the minority $(4.1 \%)$ rated themselves rare users of social media (Table 2).

Table 2: Degree of social media use at night

\begin{tabular}{|c|c|c|}
\hline Type of user & Frequency & Percentage \\
\hline Rare user & 24 & 4.1 \\
\hline Moderate user & 85 & 14.7 \\
\hline Heavy user & 150 & 25.9 \\
\hline Very heavy user & 320 & 55.3 \\
\hline Total & 579 & 100.0 \\
\hline
\end{tabular}

\section{Students' Logging Status and Number of Followers}

Respondents were asked to determine how long they stayed logged on their social media sites during the night. Table 3 reveals that $86 \%$ of the respondents were permanently online during the night, while $80.3 \%$ were ever online during both day and night times. The results further revealed that $13.3 \%$ of the respondents had 1-10 followers, $12.4 \%$ had 11-50 followers, whereas $11.7 \%$ had 51-100. Additionally, the majority $(62.5 \%)$ had above 500 followers (Table 3).

Table 3: Logging status and the number of followers

\begin{tabular}{|l|c|c|c|}
\hline \multicolumn{1}{|c|}{ Variables } & Values & Frequency & Percentage \\
\hline $\begin{array}{l}\text { Permanently offline during bedtime } \\
\text { till morning }\end{array}$ & No & 498 & $86.0 \%$ \\
\hline $\begin{array}{l}\text { Permanently online during day and } \\
\text { night }\end{array}$ & Yes & 81 & $14,0 \%$ \\
\hline \multirow{3}{*}{$\begin{array}{l}\text { Number } \\
\text { of Followers }\end{array}$} & No & 465 & $19.7 \%$ \\
\cline { 2 - 4 } & $1-10$ & 77 & $80.3 \%$ \\
\cline { 2 - 4 } & $11-50$ & 72 & $13.3 \%$ \\
\cline { 2 - 4 } & $51-100$ & 68 & $11.7 \%$ \\
\hline
\end{tabular}


In addition, one of the main concerns that the discussants highlighted was the demand for responding to the increasing numbers of followers on social media. Most of them reported that it was not easy to log out of social media as they had more than 100 followers. The quest to attend to their demands as well as to the needs of their followers ignited frequent visitations to their preferred platforms. Below are extracts from three discussants expressing their views on this issue:

I frequently check my phone before I sleep to see what is going on or what has come up. When I find an update, I respond, view, read, and post new messages, thereafter wait for feedback from friends while surfing other areas. Moreover, I have more than 600 social media friends, especially on Facebook, so I fear losing essential information from them (FGD 2).
The number of my followers is not static; it changes weekly. Currently, I have 650 followers with whom I constantly interact' (FGD 3).

I have above 1000 friends, and I receive a lot of requests from them on a daily basis, particularly on Facebook as well as other platforms. So I have less hours sleeping because of the need to attend to them" (FGD 6).

\section{Student's quantity of sleep}

Respondents were asked to estimate the number of hours they spent sleeping at night. As shown in Table $4,19.7 \%$ reported that they slept for 8 hours and above whereas the majority (51.3\%) slept between 5 and 7 hours; and the rest $(29.0 \%)$ slept below 5 hours. Overall, $80.3 \%$ of the respondents slept for less than 8 hours.

Table 4: Time student spent sleeping after visiting social media

\begin{tabular}{|c|c|c|c|}
\hline Time & Frequency & Percentage & Cumulative Percent \\
\hline 8 hours and above & 114 & 19.7 & 19.7 \\
\hline Between 5 and 7 hours & 297 & 51.3 & 161.4 \\
\hline Below 5 hours & 168 & 29.0 & 100.0 \\
\hline Total & 579 & 100 & \\
\hline
\end{tabular}

Findings from focus group discussions yielded similar trends in comparison to those of the quantitative outcome. Majority of the discussants were spending less than 7 hours, while very few reported spending more than 8 hours of sleep. For example, one discussant gave a worrying comment: "each time I am on Facebook at night, the hours I spend does not matter. Sometimes I break the night interacting with friends particularly those whose status show online" (FGD1).

\section{REASONS FOR USING SOCIAL MEDIA AT NIGHT}

Table 5 shows the reasons that compel respondents to use social media for extended hours during bedtime. Most respondents used social media to read the latest news $(93.6 \%)$, check what was going on in the world $(91.5 \%)$, update their status $(84.8 \%)$, public messaging (81.8\%), seeing friends on WhatsApp videos $(75.6 \%)$, posting selfies $(71.6 \%)$, following their favourite stars $(68.5 \%)$, reducing restlessness $(63.0 \%)$, and spreading rumors $(46.2 \%)$.

Table 5: Reasons for using Social Media at Night

\begin{tabular}{|l|c|c|c|}
\hline \multirow{2}{*}{} & \multicolumn{2}{|c|}{ Responses } & \multirow{2}{*}{ Percent of Cases } \\
\cline { 2 - 3 } & $\mathbf{N}$ & Percent & Percing \\
\cline { 2 - 3 } & 541 & $13.8 \%$ & $93.6 \%$ \\
\hline Reading latest news and updates & 529 & $13.5 \%$ & $91.5 \%$ \\
\hline Updating own status & 490 & $12.5 \%$ & $84.8 \%$ \\
\hline Public messaging & 473 & $12.1 \%$ & $81.8 \%$ \\
\hline Love to see a friend on WhatsApp videos & 437 & $11.2 \%$ & $75.6 \%$ \\
\hline Posting selfies & 414 & $10.6 \%$ & $71.6 \%$ \\
\hline Follow my favourite stars & 396 & $10.1 \%$ & $68.5 \%$ \\
\hline To playing games & 364 & $9.3 \%$ & $63.0 \%$ \\
\hline Spreading rumors & 267 & $6.8 \%$ & $46.2 \%$ \\
\hline Total & 3911 & $100.0 \%$ & $676.6 \%$ \\
\hline
\end{tabular}


Findings from FDGs revealed that most discussants used social media mainly to connect with friends, seek information from online communities One discussant said that:

Social media makes my relationship more splendid and more trustworthy. With its power, I chat with friends and get more information from them (FGD 5).

In addition majority of the discussants narrated that social media was an agent of socialization as it provided a source of entertainment. This was captured in the statement from one discussant below:

I love spending time socializing through social media at night. Facebook provides me with entertainment. I like downloading funny fancy video materials and watch them besides Facebook is quite an excellent socializing venture (FGD 3 ).

Figure 1reveals that $66.8 \%$ found it difficult to sleep because of fear of missing out; $66.2 \%$ use to experience headaches or pain in the eyes; $64.7 \%$ could not sleep because of thinking about things they had not done on social media; $64.4 \%$ of the respondents reported that their mobile phone screen lights kept on disturbing them even when they were switched off during bedtime; $64.3 \%$ of the respondents reported that they often dosed during lessons due to lack of adequate sleep at night. Finally $60.8 \%$ woke up prematurely in the night to attend to social media demands.

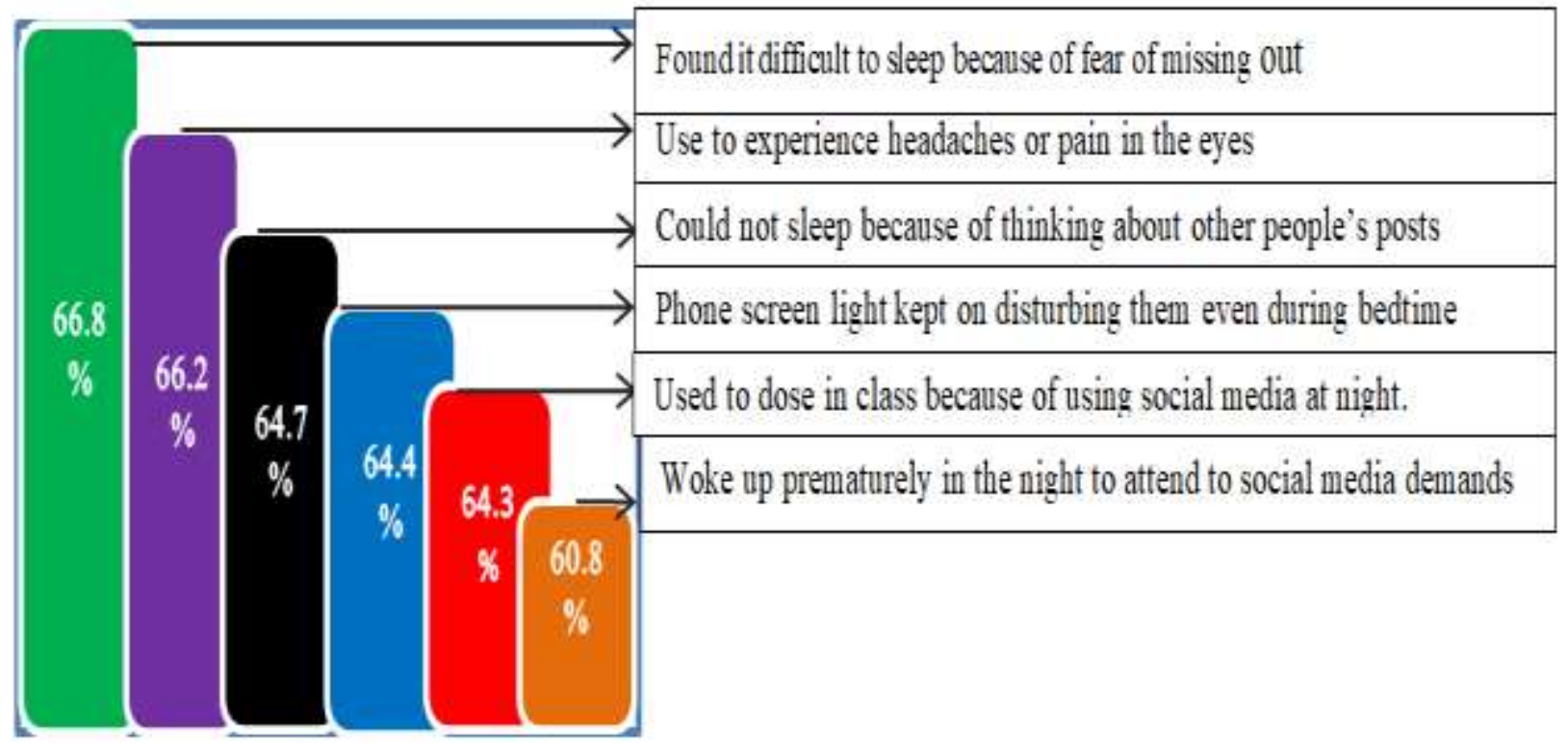

\section{CSMU and students' quality of sleep}

Quality of sleep was measured using six (6) items which were scored on a 1-5 Likert scale. In this regard, sleep quality were classified as Very poor quality (24-30), poor quality (18-23), good quality (12$17)$, and very good quality (6-11). Summarized in Table 6, the results reveal that $39.6 \%$ of the

\section{al media use at night}

respondents experienced very poor quality sleep, $23.5 \%$ experienced poor quality sleep, $26.4 \%$ experienced good quality sleep, and $10.5 \%$ experienced very good quality of sleep. When the first two levels (very high and high) are combined, the results revealed that $63.1 \%$ of the respondents experienced very poor quality sleep behaviors.

Table 6: Classification of quality of sleep

\begin{tabular}{|c|c|c|c|}
\hline & Frequency & Percentage & Cumulative Percent \\
\hline Very poor quality & 229 & 39.6 & 39.6 \\
\hline Poor quality & 136 & 23.5 & 63.0 \\
\hline Good quality & 153 & 26.4 & 89.5 \\
\hline Very good quality & 61 & 10.5 & 100 \\
\hline Total & 579 & 100.0 & \\
\hline
\end{tabular}


A Pearson correlation test was conducted at alpha $=0.01$ to examine the relationship between CSMU and sleep quality among the students during bedtime. Results as presented in Table 7 below revealed that CSMU was negatively correlated with quality of sleep $(\mathrm{rho}=-0.113, \mathrm{p}=0.006)$.

Table 7: CSMU and Quality of Seep Correlation

\begin{tabular}{|c|c|c|c|c|c|}
\hline Health conditions & Mean & SD & $\begin{array}{c}\text { Pearson } \\
\text { Correlatio } \\
\text { n Statistic }\end{array}$ & $\begin{array}{c}\text { P- } \\
\text { Value }\end{array}$ & Comment \\
\hline $\begin{array}{c}\text { Degree of quality of } \\
\text { sleep }\end{array}$ & 14.41 & 6.861 & $-.113^{* *}$ & .006 & Negative correlation \\
\hline \multicolumn{7}{|c|}{$* *$ When the correlation is significant at the 0.01 level (2-tailed). } \\
\hline
\end{tabular}

Discussants were also asked to narrate their views about their social media habits around bedtime and what they thought social media had on their sleep quality. The findings were categorized into three subthemes, namely: difficulties falling asleep, premature awakening and sleep disturbances due to unhealthy related condition (Table 8).

Table 8: Impact of excessive usage of social media at night on quality of sleep

\begin{tabular}{|c|l|}
\hline Theme & Extracted Narration \\
\hline $\begin{array}{c}\text { Difficulties } \\
\text { falling sleep }\end{array}$ & $\begin{array}{l}\text { Most of the times, I fail to catch up on sleep because of my quest to be fully updated all the } \\
\text { time with online feeds. But sometime, I blame myself. You know, I would set time to myself } \\
\text { that I will sleep at 21:00 hours, but once I open my Facebook page, I lose track of time, } \\
\text { and I end up sleeping very late, mostly around 02:00 hours (FGD 4). }\end{array}$ \\
\hline $\begin{array}{c}\text { Premature } \\
\text { awakening }\end{array}$ & $\begin{array}{l}\text { I encounter the problem of sleepless nights due to the desire to maintain online } \\
\text { interaction. So I wake up even in the night prematurely to interact, and sadly, it becomes } \\
\text { challenging falling asleep again. It has impaired my night sleeping style (FGD 3). }\end{array}$ \\
\hline $\begin{array}{c}\text { Sleep } \\
\text { disturbances } \\
\text { due to } \\
\text { unhealthy } \\
\text { related } \\
\text { conditions }\end{array}$ & $\begin{array}{l}\text { My eyes sometimes pain a lot when I stay long online. Although I know that staying long } \\
\text { online is quite harmful, I can't back out logging online because it makes my interactive } \\
\text { social life to be at peace. So, I check the phone frequently, and in the end, I lose track of } \\
\text { sleeping time (FGD 5). }\end{array}$ \\
$\begin{array}{l}\text { The phone light keeps on reflecting in my eyes even if the phone is off. So I struggle to } \\
\text { sleep, my eyes pain and sometimes I develop body weakness and even headache, which } \\
\text { makes me inattentive in other activities. I also doze off during boring lectures (FGD 1). }\end{array}$ \\
\hline
\end{tabular}

\section{DISCUSSION}

This study has established that students were using social media during bedtime to read the latest news, check what was going on worldwide, update their status, public messaging, see friends on WhatsApp videos, post selfies, follow their favourite stars, reduce restlessness and spread rumors. These motives are similar to what prior scholar obtained (Lin \& Lu., 2011; Sharma \& Shukla, 2016; Cramer \& Inkster, 2017; Buran \& Doğan, 2018; Meşe \& Aydın, 2019). However, the general explanation in the current study may be that students seem to point at using social media at night for leisure gratifications driven by entertainment and socializing. In this regard, the motives seem to point at the provision of pleasure as they interact with many friends. This reflects college student's strong incentives to pursue their inner and external gratifications at night. However, based on the constant increase in the number of captivity apps and continued technological advancements (Meşe \& Aydın, 2019; Kemp, 2021), the implication could be that students will continue with such a trend more than ever before in the near future. As such, the situation seems to be alarming and require urgent attention.

Furthermore, a significantly poor quality of sleeping behaviour among the students was revealed with varying consequences such as difficulties falling asleep, premature awaking and sleep disturbances due to unhealthy related conditions. The findings of this study are in line with previous studies (Galambos et al., 
2011; Levenson et al., 2017; Garett et al., 2018: Lin et al., 2019). The findings have established a weak negatively correlated between excessive use of social media and quality of sleep. However, finding appears to be situational or bio-directional, and it depends on the student's behavioural usage of social media during bedtime. The results imply that when a student engages in excessive use of social media poor quality becomes apparent. Similarly, when a student experiences low levels of social media use this may results into high levels of good quality sleep. In this regard, the finding may support the discoveries that were done by Yang et al. (2019) and Lin et al. (2019). These studies found a negative association between the degrees of Internet addiction and sleep quality.

\section{CONCLUSION}

This study has established pleasure as the motives that compelled students to engage in excessive social media usage, resulting in less sleep during bedtime. Besides, results demonstrate a significant relationship between excessive use of social media and the quality of sleep. Therefore, the researchers recommend that college managements should conduct awareness programs to educate students on the negative effects of excessive usage of social media, particularly during bedtime.

\section{Acknowledgments}

This work emerged from a thesis submitted to the University of Zambia in partial fulfilment of Degree of Doctor of Philosophy in Education Psychology by the second author.

\section{REFERENCE}

1. Abdalqader M.A., Ariffin I.A., Ghazi H.F, Mohammed Faez AboBakr M.F. \& Fadzil M.A (2018)Prevalence Of Insomnia And Its Association With Social Media Usage Among University Students. Fol Med Indones, Vol. 54 No. 4 International Medical School (IMS), Management \& Science University (MSU), Shah Alam, Selangor, Malaysia

2. Adams, S.K., Williford, D., Vaccaro, A., Kisler, T.S., *Francis, A., \& Newman, B. (2016). The Young and the restless: Socializing trumps sleep, fear of missing out, and technological distractions in first year college students. International Journal of Adolescence and Youth 1-12. https://doi.org/10.1080/02673843.2016.1181557

3. Akoglu, H. (2018). User's guide to correlation coefficients. Turkish Journal of Emergency Medicine.18 91-93: Date accessed 1st August, 2020 from https://doi.org/10.1016/j.tjem.2018.08.001

4. Akakandelwa A. \& Walubita G. (2017). Students 'Social Media Use and its Perceived impact on their Social Life: A Case Study of the University of Zambia. The International Journal of multiDisciplinary research. ISSN: 3471-7102. www.ijmdr.net.

5. Baskarada, S. \& Koronios, A. (2018). A philosophical discussion of qualitative, quantitative, and Mixed methods research in social science. Qualitative Research Journal, 18(1), 2-21.

6. Bhat $S$, (2017) Social networking sites and mental health: A review Volume 2; Issue 5; September 2017; Page No. 357-360 International Journal of Advanced Educational Research ISSN: 2455-6157. Date retrived 9th December, 2019.

7. Buran Köse, Ö., \& Doğan, A. (2018). The relationship between social media addiction and self-esteem among. Turkish university students. Addicta: The Turkish Journal on Addictions, 6, 175-190.

http://dx.doi.org/10.15805/addicta.2019.6.1.0036.

Date accessed 4th June, 2010

8. Buysse, D.J., Reynolds, C.F, Monk TH. (1989). The Pittsburgh sleep quality index: A new instrument for psychiatric practice and research. Psychiatry Res; 28(2):193-213. 17th May, 2019.

9. Cole J.C, Motivala, S.J, Buysse, D.J, Oxman MN, Levin M.J, Irwin M.R. (1989). Validation of a 3factor scoring model for the Pittsburgh sleep quality index in older adults.. Sleep. ;29(1):112-6. 17th May, 2019.

10. Cramer, S., \& Inkster, B. (2017). Social media and young people's mental health and wellbeing. (Report.) London, England: Royal Society for Public Health (UK) and Young Health Movement (UK).

11. Creswell, J. W. \& Creswell, J. D. (2018). Research design: Qualitative, Quantitative, and Mixed Methods Approaches (5th ed). Los Angeles, CA. SAGE.

12. Dearborn, E. (2014). My official definition of social media. Retrieved from https://www.linkedin.com/pulse/2014092921574547165795. Date 16th August 2018.

13. Galambos, N. L., Howard, A. L., \& Maggs, J. L. (2011). Rise and fall of sleep quantity and quality with student experiences across the first year of university. Journal of Research on Adolescence, 21, 342-349. doi:10.1111/j.1532-7795.2010.00679.

14. Garett, R., Liu, S., \& Young, S. D. (2018). The relationship between social media use and sleep quality among undergraduate students. Information, Communication \& Society, 21,163$173 . \quad$ doi:10.1080/1369118X.2016.1266374. Accessed 10th January 2019.

15. Hershner $D$ \& Chervin $R$ (2014) Causes and consequences of sleepiness among college students open access to scientific and medical research Department of Neurology, University of Michigan, Ann Arbor, MI, USA DOI https://doi.org/10.2147/NSS.S62907 
16. Hirshkowitz, M., Whiton, K., Albert, S. M., Alessi, C., Bruni, O., DonCarlos, L., Hazen, N., Herman, J., Adams Hillard, P. J., Katz, E. S., KheirandishGozal, L., Neubauer, D. N., O'Donnell, A. E., Ohayon, M., Peever, J., Rawding, R., Sachdeva, $R$. C., Setters, B., Vitiello, M. V., \& Ware, J. C. (2015). National Sleep Foundation's updated sleep duration recommendations: Final report. Sleep Health, 1(4),

233 243. https://doi.org/10.1016/j.sleh.2015.10.004

17. Kemp, (2021) Digital 2021: The Latest Insights into the 'State Of Digital' Data accessed 8th February 2021, from https://wearesocial.com/blog/2021/01/digital-2021the-latest-insights-into-the-state-of- digital.

18. Lancaster,. H. (2015). Zambia telecoms, Mobile and Broadband-Statistic and Analysis. Paul Budde communication Bucketty NSW 2250.

19. Levenson, J. C., Shensa, A., Sidani, J. E., Colditz, J. B., \& Primack, B. A. (2017). Social media use before bed and sleep disturbance among young adults in the United States: A nationally representative study. Sleep, 40(9), 1-7 https://doi.org/10.1093/sleep/zsx113

20. Lin P-H, Lee Y-C, Chen K-L, Hsieh P-L, Yang S-Y and Lin Y-L (2019) The Relationship Between Sleep Quality and Internet Addiction Among Female College Students. Front. Neurosci. 13:599. doi: 10.3389/fnins.2019.00599.

21. Lin, K.Y. \& Lu, H.P. (2011). Why people use social networking sites: an empirical study integrating network externalities and motivation theory. Computers in Human Behavior, 27(3), 1152-1161.

22. Lund, H. G., Reider, B. D., Whiting, A. B., \& Prichard, J. R. (2010). Sleep patterns and predictors of disturbed sleep in a large population of college students. The Journal of adolescent health: official publication of the Society for Adolescent Medicine, 46(2), 124-132. https://doi.org/10.1016/j.jadohealth.2009.06.016

23. Scott H, Biello SM, Woods HC (2019). Social media use and adolescent sleep patterns: crosssectional findings from the UK millennium cohort study. BMJ Open;9:e031161. doi:10.1136/ bmjopen-2019-031161. Date accessed 23rd May, 2020.1

24. Meşe, C. \& Aydın, G. S. (2019).The use of social networks among university students Vol. 14(6), pp. 190-199, DOI: 10.5897/ERR2018.3654 Article Number: ISSN: 1990-3839. Date accessed 23rd May, 2020.

25. Oche OM, Gana JG, Yahaya M, Khalid I, \& Sambo A, (2019)Prevalence and Effect of Social Media on Sleep among Students of Higher Institutions in Sokoto Metropolis, Sokoto State Nigeria. Ann Med Health Sci Res. 2019;9:729-735.

26. Petersen, C., \& Johnston, K. A. (2015). The impact of social media usage on the cognitive social capital of university students. Informing Science:
The International Journal of an Emerging Transdiscipline, 18, 1-30.

27. Sharma, A. \& Shukia, A.K. (2016). Impact of social messengers Especially WhatsApp on Youth: A sociological study. International journal of Advance Research and innovation Ideas in education 2(5), 367-375.

28. Silomba, H.J., Akakandelwa, A. \& Kasonde, S.N. (2021). Student's Perspectives on Prevention Strategies of Social Media Addiction Effects in Selected Colleges of Education on the Copperbelt Zambia. Journal of Education and Practice www.iiste.org Vol.12, No.3, DOI: 10.7176/JEP/123-17.

29. Silomba HJ, Akakandelwa A. \& Kasonde SN (2021). Association between Social Media Addiction and Depression of Students in Colleges of Education on the Copperbelt Province, Zambia International Journal of Humanities Social Sciences and Education (IJHSSE) Volume 8, Issue 2, PP 157-165 https://doi.org/10.20431/23490381.0802015 .

30. Statista, (2019). Statistics and facts about social networks. Retrieved from https://ceoworld.biz/2019/03/03/the-20-top-mostused-social-networking-sites-and-apps-in-theworld-2019/

31. Smith, A., \& Anderson, M. (2018). Social media use in 2018. Date retrieved 10th May 2019from http://www.pewinternet.org/2018/03/01/s ocial-media-use-in-2018/

32. Vorderer, P., Kr€omer, N., \& Schneider, F. M. (2016). Permanently online-Permanently connected: Explorations into university students' use of social media and mobile smart devices. Computers in Human Behavior, 63, 694-703.

33. Watson $N F$, Badr MS, Belenky $G$, Bliwise $D L$, Buxton OM, Buysse D, Dinges DF, Gangwisch J, Grandner MA, Kushida C, Malhotra RK, Martin $J L$, Patel SR, Quan SF, Tasali E. (2015)(Recommended amount of sleep for a healthy adult: a joint consensus statement of the American Academy of Sleep Medicine and Sleep Research Society;38(6):843-844. doi: 10.5665/sleep.4716

34. Xu X, Lin, Q. Zhang, Y. Zhu, R. Sharma, M. Zhao, $Y$. (2016). Influence of WeChat on sleep quality among undergraduates in Chongqing, China: A cross sectional study. Springer Plus. Dec 1:5 (1):2066. Date accessed 17th May, 2019.

35. Yang, S.Y., Chen, K.L., Lin, P.H. \& Wang, P.Y. (2019). Relationships among health-related behaviors, smartphone dependence, and sleep duration in female junior college students. Soc. Health Behav. 2:26. Date accessed 25th June, 2020.

36. Zheng, W., Yuan, C., Chang, W. \& Wu, Y. (2016). Profile pictures on social media: Gender and regional differences. Computers in Human Behavior, 63, 891-898. 
37. ZICTA (2018). National Survey on access and usage of Information and Communication Technologies by Households and Individuals. A Demand side assessment of access and usage of ICTs in Zambia. Date accessed 8th August, 2020. 